\title{
Enhanced decoupled current control with voltage Compensation for modular multilevel converter (MMC) based STATCOM
}

\author{
Abdurrahman Umar Lawan', Haider A.F. Almurib² ${ }^{2}$, Jeen G. Khor ${ }^{3}$ \\ ${ }^{1,2,3}$ Department of Electrical \& Electronic Engineering, University of Nottingham, Malaysia Campus, 43500 \\ Semenyih. Malaysia \\ ${ }^{1,2}$ Department of Electrical Engineering, Husseini Adamu Federal Polytechnic, 10 Kano Road, Kazaure, Nigeria
}

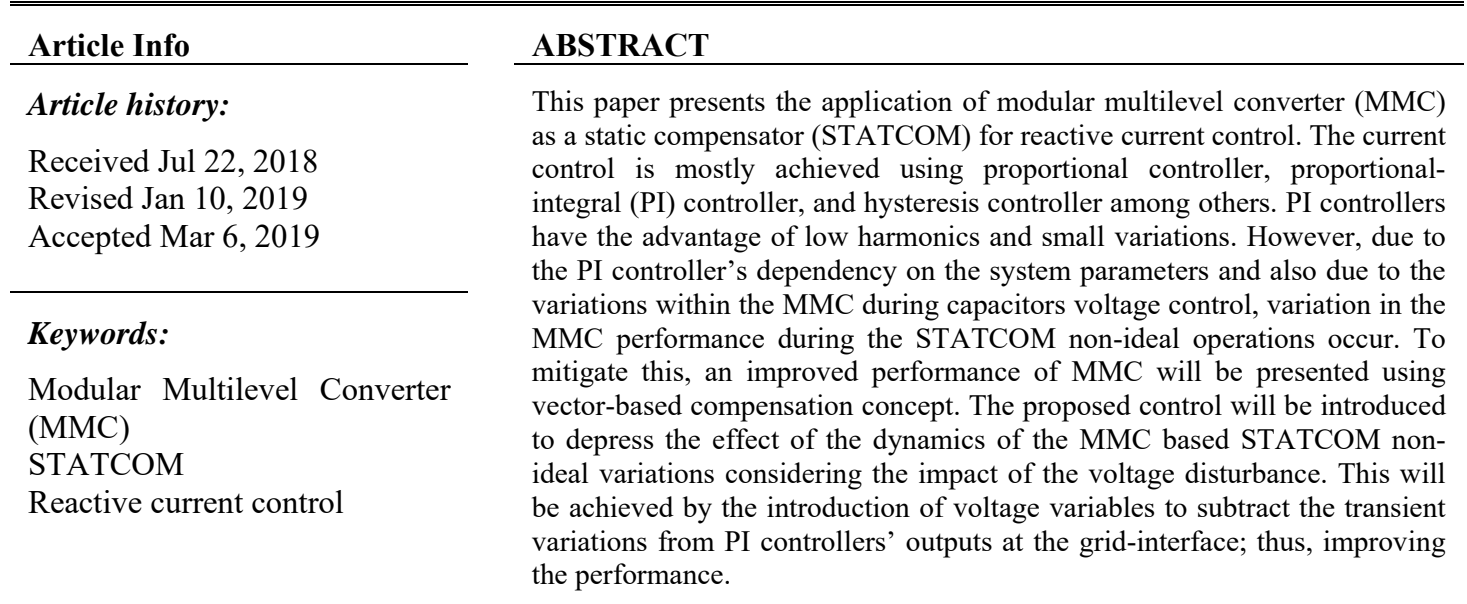

Copyright (C) 2019 Institute of Advanced Engineering and Science. All rights reserved.

\section{Corresponding Author:}

Abdurrahman Umar Lawan,

University of Nottingham, Malaysia Campus,

43500 Semenyih. Malaysia,

Departement of Electrical and Computer Engineering,

E-mail:kecx4aua@nottingham.edu.my

\section{INTRODUCTION}

There are many types of disturbances which can affect or precisely reduce the grid power quality (PQ) $[1,2]$. Power disturbances depending on their magnitudes, nature of the end users, intermediary power devices among others can affect the quality of the grid system significantly. The degrading of power quality can be due to voltage distortions, sags, voltage transients, swells, flickers and unbalances in voltages, interruptions, and current spikes among others. The static compensators (STACOMs) are shunt devices, and their reactive power (VAR) compensations have been used in mitigating these power problems with good transient and dynamic performance [3-9]. STATCOM applications for VAR compensation and stability studies have been employed based on different control schemes [10-12]. Lawan et al. [13, 14] have employed the direct approach to improving the power factors using MMC based STATCOMs. The power factors were improved with good transient performance. However, the capacitor voltage disturbance was not considered in the compensation scheme. This could have improved the transient response of the system. Haw et al. [12] and Kaw et al. [15] proposed voltage support using STATCOM. In [15], there were good transient performances of the STATCOM, which was employed using proportional (P) controllers. However, the issue of individual capacitor cell voltage variation with respect to the total three-phase arithmetical capacitor voltage was not considered in the compensation. This could have improved the active power balancing 
between the STACOM and the grid. Moreover, incorporating the voltage disturbance and capacitor balancing control in [15] could have added complications to the selective harmonic elimination (SHE) modulation [16].

A well-tuned PI-controller can yield response with zero or minimum steady state error within a small rise time. However, PI controllers may have some drawbacks which includes the high settling time $[17,18]$. It has also been reported that PI controllers have poor transient response compared to other common controllers such as hysteresis and ramp time controllers in voltage source inverter (VSI) STATCOMs [18]. For example in [19], PI control was employed for STATCOM voltage regulations, but oscillation occurred in the response and produced a poor transient response even though there was minimal steady-state error in the command track. Amir et al. in [20] presented PI controller in which its gain was obtained by an automatic gain process, proposed to reduce the high-source impedance oscillation effect and to lessen the phase-locked loop (PLL) inherent delay effect. There was a good stability enhancement due to reduced oscillation during the steady-state performance. The control technique was further employed in [21] to reduce the same effect of the PLL. However, overcurrent that was three times higher than the rated current was produced by the STACOM during the load step change. This overcurrent imposed the use of increased rated power devices. Another approach is the use of the biologically shaped PI-controllers [22-25]. The objective of this paper is to introduce a simple and less computationally heavy algorithm unlike the algorithms in [25] and [23]. It is also, to exploit the feature of the external compensation on controllers proposed by the authors in [12] for VAR compensation and control enhancement. Since the MMC has little active power exchange externally with the grid for the typical STATCOM application [26], an improved response can be achieved by compensating both the negligible active power and the reactive power. In other words, unlike in [12], this proposed algorithm does not sacrifice the contribution of the of d-axis current which is usually assumed negligible. From [27], instead of adjusting the PI-controllers gains to achieve improved response under different operations, a transient compensator to be derived will be augmented with a capacitor voltage injection [28] to introduce voltage compensation. This compensation will enhance the control of the PIcontrollers under different operations. The proposed algorithm will be derived in this paper to produce opposite voltage support to the d,q-PI controller output variables $\left(Q_{d}\right.$ and $\left.Q_{q}\right)$. This will be in response to the STATCOM d-axis and q-axis variations in the current control. Furthermore, the introduction of voltage compensation will mitigate the variation impact from the growing number of SM capacitors in the MMC applications. Unlike [29], this paper will not replace the PI controllers which have the advantage of less current distortion with the hysteresis-like controllers that exhibit high distortion [29]. Instead, the proposed control will incorporate the advantage of the use of the PI controllers and super-impose them with the proposed voltage compensator.

\section{MODULAR MULTILEVEL CONVERTER (MMC) INVERTER BASED STATCOM}

Figure 1 shows an MMC based STATCOM system connected to a power grid. The amount of required power that will produce the required STATCOM current $I_{f}$ which flows through the coupling impedance $Z_{f}$ depends on the difference in voltage between the STATCOM AC output voltage (i.e. $V_{c}$ ) and. the grid voltage at the point of coupling (PCC) (i.e. $V_{f}$ ).

If the source impedance (i.e. source inductance $L_{s}$ and source resistance $R_{s}$ ) is assumed negligible, the grid source voltage (i.e. $V_{s}$ ) would be the same as $V_{f}$. The system voltage relationship is illustrated in (1), where $\delta$ represents the phase angle between the STATCOM voltage (i.e. $V_{c}$ ) and the grid voltage (i.e. $\left.V_{f}\right)$.

$$
I_{f}=\frac{V_{f}-V_{c} \angle \pm \delta}{Z_{f}}
$$

Based on (1) using the diagram of Figure. 1 the system transfer function with an angular frequency $\omega$ is given by:

$$
\left[\begin{array}{l}
V_{c d} \\
V_{c q}
\end{array}\right]=\left[\begin{array}{l}
V_{f d} \\
V_{f q}
\end{array}\right]+\omega\left(L_{f}+\frac{L}{2}\right)\left[\begin{array}{l}
I_{f q} \\
-I_{f d}
\end{array}\right]-\left(R_{f}+\frac{R}{2}\right)\left[\begin{array}{l}
I_{f d} \\
I_{f q}
\end{array}\right]-\left(L_{f}+\frac{L}{2}\right) \frac{d}{d \boldsymbol{t}}\left[\begin{array}{l}
I_{f d} \\
I_{f q}
\end{array}\right]
$$

Int J Pow Elec \& Dri Syst, Vol. 10, No. 3, Sep 2019 : $1483-1499$ 


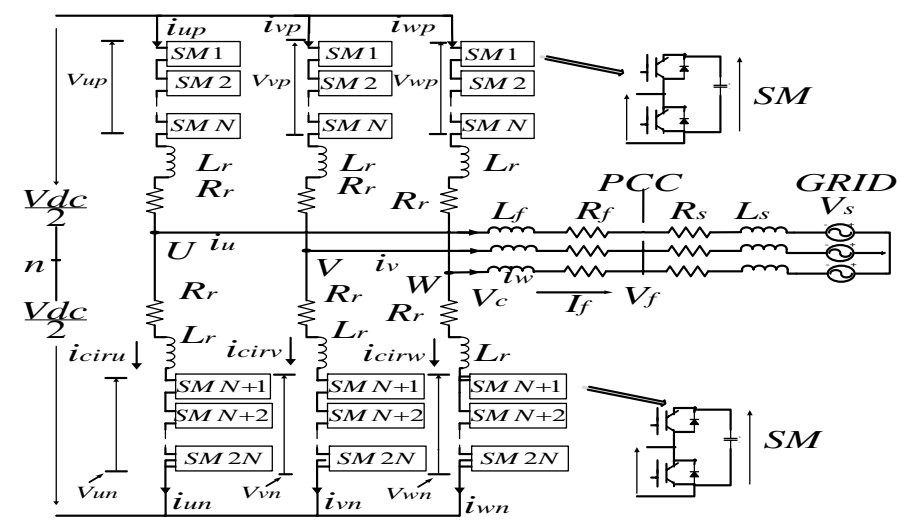

Figure. 1.The three-phase MMC based STATCOM connected to the grid system

In (2), the $I_{f q}$ is the reactive current of the MMC while $I_{f d}$ is the active current. $L_{f}$ and $R_{f}$ are the coupling inductance and resistance respectively. $V_{c d}$ is the MMC three phase output voltage in the d-axis usually aligned with the grid voltage using the phase-locked loop. $V_{c q}$ is the MMC output voltage in the qaxis. $V_{f d}$ and $V_{f q}$ are the grid d-axis and q-axis voltages respectively.

In Figure. 1, the per-phase current can be considered as $i_{k}$. The sub-subscript ${ }_{k}$ represents any of the three-phases (u, v or w). The lower and upper arm currents are denoted as $\boldsymbol{i}_{k p}$ and $\boldsymbol{i}_{k n}$ respectively. The circulating current is denoted as $i_{\text {cirk }}$. The $V_{c k}$ is the MMC output voltage and can be obtained by controlling the upper arm voltage $V_{k p}$ and the lower arm voltage $V_{k n}$. The $V_{d c}$ is the equivalent direct current (DC) voltage across the arms. The cumulative MMC-to-grid inductance and resistance are then defined by (3).

$$
L_{\tau}=L_{f}+\frac{L_{r}}{2} ; R_{\tau}=R_{f}+\frac{R_{r}}{2}
$$

Integrating (2) between the present sample (k) (i.e. sub-script k) and the next sample $(k+1)$ over a given period (i.e. $T_{i(d, q)}$ ) during the current control will give:

$$
\begin{aligned}
& Q_{d}(k, k+1)=V_{f d}(k, k+1)-V_{c d}(k, k+1)+\omega L_{T} I_{f q}(k, k+1)-R_{T} I_{f d}(k) \\
& Q_{q}(k, k+1)=V_{f q}(k, k+1)-V_{c q}(k, k+1)-\omega L_{T} I_{f d}(k, k+1)-R_{T} I_{f q}(k)
\end{aligned}
$$

The relationship between the rates of change of the MMC output $d$, q currents with time can be expressed in terms of the variables $Q_{d}(k, k+1)$ and $Q_{q}(k, k+1)$ given in (6) and (7).

$$
\begin{aligned}
& \frac{d I_{f d}}{d t}=\frac{Q_{d}(k, k+1)}{L_{T}} \\
& \frac{d I_{f q}}{d t}=\frac{Q_{q}(k, k+1)}{L_{T}}
\end{aligned}
$$

The d,q-variables $Q_{d}(k, k+1)$ and $Q_{q}(k, k+1)$ in (6) and (7) can be obtained from the outputs of PI controllers as 


$$
\begin{aligned}
& Q_{d, q}(k, k+1)=K_{P_{-} i(d, q)}\left(I_{f(d, q)}(k+1)-I_{f(d, q)}(k)\right)+ \\
& K_{I_{-} i(d, q)} \int\left(I_{f(d, q)}(k+1)-I_{f(d, q)}(k)\right) d t
\end{aligned}
$$

These d,q-variables can be used to obtain the corresponding d,q-voltage components for the modulation of the MMC during the same sample period as follows:

$$
\begin{aligned}
& V_{c d}(k, k+1)=V_{f d}(k, k+1)+\omega L_{T} I_{f q}(k, k+1)-R_{T} I_{f d}(k)-Q_{d}(k, k+1) \\
& V_{c q}(k, k+1)=V_{f q}(k, k+1)-\omega L_{T} I_{f q}(k, k+1)-R_{T} I_{f q}(k)-Q_{q}(k, k+1)
\end{aligned}
$$

where the d,q proportional and integral controllers' gains $K_{P_{-} i(d, q)}$ and $K_{I_{-} i(d, q)}$ with the sample rate $T_{i(d, q)}$ can be obtained [12] respectively as

$$
\begin{aligned}
& K_{P_{-}(d, q)}=\frac{L_{T}}{T_{i(d, q)}}+\frac{R_{T}}{2} \\
& K_{I_{-} i(d, q)}=K_{P_{-} i(d, q) *} T_{i(d, q) *} \frac{R_{T}}{L_{T}}
\end{aligned}
$$

The PI controllers fast response make the STATCOM output d,q current references (i.e. $\left.I_{f(d, q)}(k+1)\right)$, with the d,q-PI variables (i.e. $\left.Q_{(d, q)}(k, k+1)\right)$ of the next sample period meet up with the current sample d,q current references $I_{f(d, q)}^{*}(k)$ with d,q-PI variables $Q_{(d, q)}(k)$ respectively as follows:

$$
\begin{aligned}
& I_{f d}(k+1)=I_{f d}^{*}(k) \\
& I_{f q}(k+1)=I_{f q}^{*}(k)
\end{aligned}
$$

Equations (13) and (14) can further be written in an average form as:

$$
\begin{aligned}
& \frac{1}{2} I_{f d}(k)+\frac{1}{2} I_{f d}^{*}(k)=I_{f d}(k, k+1) \\
& \frac{1}{2} I_{f q}(k)+\frac{1}{2} I_{j q}(k)=I_{f q}(k, k+1)
\end{aligned}
$$

Expanding (8) in separate d,q forms using (13)and (14) gives:

$$
\begin{aligned}
& Q_{d}(k)=K_{P_{-} i(d)}\left(I_{f l}^{*}(k)-I_{f d}(k)\right)+K_{I_{-} i(d)} \int\left(I_{f d}^{*}(k)-I_{f d}(k)\right) d t \\
& Q_{q}(k)=K_{P_{-} i(q)}\left(I_{f q}^{*}(k)-I_{f q}(k)\right)+K_{I_{-} i(q)} \int\left(I_{f^{\prime}}^{*}(k)-I_{f q}(k)\right) d t
\end{aligned}
$$

Due to the action of the PI controllers in (17) and (18). The grid voltage and the MMC based STATCOM output voltage are assumed constant within the same period, and defined as:

$$
V_{f(d, q)}(k, k+1)=V_{f(d, q)}(k)
$$




$$
V_{c(d, q)}(k, k+1)=V^{*}{ }_{c(d, q)}(k)
$$

Putting (13)-(20) into (9) and (10) gives the d,q voltage references as

$$
\begin{aligned}
& V_{c d(k)}^{*}=-K_{P_{-}(t)}\left(I_{f d}^{*}(k)-I_{f d(k)}(k)-K_{I_{-}(k)} \int\left(I_{f d}^{*}(k)-I_{f d}(k)\right) d t\right. \\
& +V_{f d}(k)+\frac{\omega L_{T}}{2}\left(I_{f q}(k)+I_{f q}^{*}(k)\right)-R_{f} I_{f d}(k) \\
& V_{c q}^{*}(k)=-K_{P_{-}(q)}\left(I_{f q}^{*}(k)-I_{f_{q}}(k)\right)-K_{I_{-}(q)} \int\left(I_{f q}^{*}(k)-I_{f q}(k)\right) d t \\
& +V_{f q}(k)-\frac{\omega L_{T}}{2}\left(I_{f d}^{*}(k)+I_{f d}(k)\right)-R I_{f q}(k)
\end{aligned}
$$

Furthermore, to impose the active power control at the three-phase grid interface, the average magnitude of the $\mathrm{d}$-axis current from the sample periods $k, k+1$ can be obtained as

$$
I_{f d}(k, k+1)=\frac{C}{T_{v d}} \overline{\mathrm{V}}_{C}(k, k+1)
$$

Where $T_{v d}$ is the average capacitor control sampling rate. $C$ is the SM capacitance as in [30].

Due to the PI controller's fast response, the STATCOM output d-axis current reference (i.e. $\left.I_{f d}(k+1)\right)$ with its corresponding three-phase average capacitor voltage $\overline{\mathrm{V}}_{c}(k+1)$ of the next sample period in (22) meets up with the current sample d-axis current reference $I_{i d}^{*}(k)$ with its corresponding reference capacitor voltage $\mathrm{V}_{C}^{*}(k)$ as follows:

$$
\begin{aligned}
& \overline{\mathrm{V}}_{C}(k+1)=\mathrm{V}_{C}^{*}(k) \\
& I_{f d}(k, k+1)=I_{f d}^{*}(k)
\end{aligned}
$$

Putting (23) and (24) into (22) gives the instantaneous active current reference $I_{f d}^{*}(k)$ as follows

$$
I_{f d}^{*}(k)=K\left(\mathrm{~V}_{C}^{*}(k)-\overline{\mathrm{V}}_{C}(k)\right)
$$

$K$ is the proportional controller gain (i.e. $\left.\frac{C}{T_{v d}}\right) . V_{C}^{*}(k)$ can be defined as the reference DC voltage for the all three-phase SM capacitors. $\overline{\mathrm{V}}_{c}(k)$ can be calculated as the arithmetical average voltage of all the SM capacitors in the three legs as

$$
\overline{\mathrm{V}}_{C}(k)=\frac{1}{3} \sum_{k=1, v, w} \overline{\mathrm{V}}_{C k}(k)
$$

For the reactive (VAR) power control at the grid-interface, the reactive current reference $I_{f q}^{*}(k)$ can be as in (27) [12] assuming all the load reactive power to be obtainable from the STATCOM.

$$
I_{f q}^{*}(k)=\frac{Q_{q}(k)}{V_{f d}(k)}=I_{L q}(k)
$$

Enhanced decoupled current control with voltage Compensation for ... (Abdurrahman Umar Lawan) 
where $Q_{L}$ and $I_{L q}$ are the reactive load power and current respectively.

Equation (21) can be simplified in terms of the variables in (17) and (18), (i.e. $Q_{d}(k)$ and $Q_{q}(k)$ ) as part of the feed forward terms [31], as follows:

$$
\begin{aligned}
& V_{c d}^{*}(k)=-Q_{d}(k)+V_{f d}(k)+\frac{\omega L_{T}}{2}\left(I_{f q}(k)+I_{f q}^{*}(k)\right)-R_{I} I_{f d}(k) \\
& V_{c q}^{*}(k)=-Q_{(q)}(k)+V_{f q}(k)-\frac{\omega L_{T}}{2}\left(I_{f d}^{*}(k)+I_{f d}(k)\right)-R_{T} I_{f q}(k)
\end{aligned}
$$

The control schemes which are averaging control, individual control, and the arm balancing control can be applied using (30) and Figure. 2-4. These controls can be extended to the three-phase configuration [34].

The meaning of the voltage symbols in Figure. 2-4 are as

$$
\begin{aligned}
& \overline{\mathrm{V}}_{c k}=\frac{1}{2}\left(\overline{\mathrm{V}}_{c p}+\overline{\mathrm{V}}_{c b s}\right) \\
& \overline{\mathrm{V}}_{c p}=\frac{1}{N} \sum_{i=1}^{N} \mathrm{~V}_{c t} \\
& \overline{\mathrm{V}}_{c b s}=\frac{1}{N} \sum_{j=N+1}^{2 N} \mathrm{~V}_{c k}
\end{aligned}
$$

- is the per-phase average capacitor voltage in the corresponding phase. $\overline{\mathrm{V}}_{C k p}$ and $\overline{\mathrm{V}}_{C k n}$ are the average capacitor voltage of the upper arm and lower arm of the corresponding phase respectively. $N$ is the number of the SM in the upper and lower arm, $V_{C k i}$ and $V_{C k j}$ are the voltages of the $i$ th and $j$ th SMs in the upper arm and lower arm respectively. $V_{C k}^{*}$ and $i_{c i r k}^{*}$ represent the reference voltage and reference circulating current in the corresponding leg respectively.

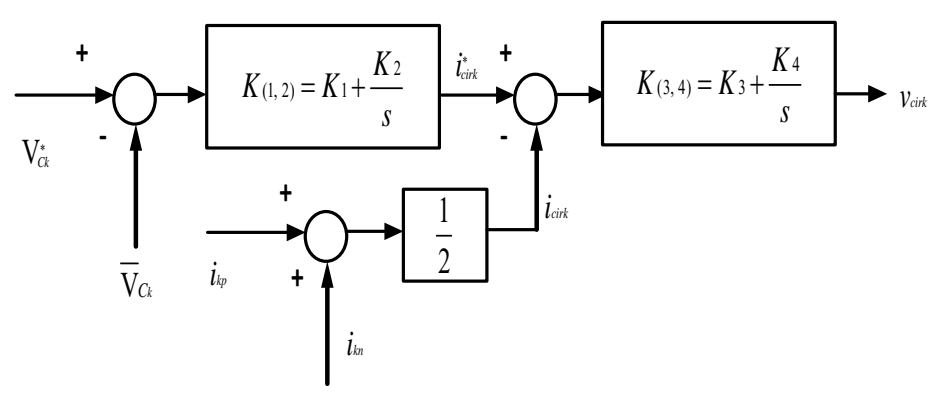

Figure 2. Block diagram of averaging control

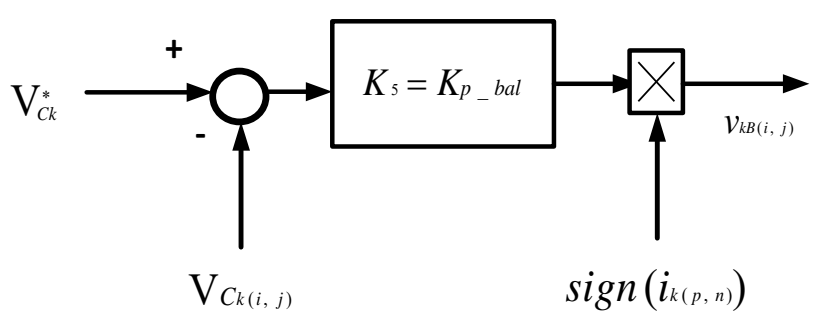

Figure 3. Individual balancing control block diagram 


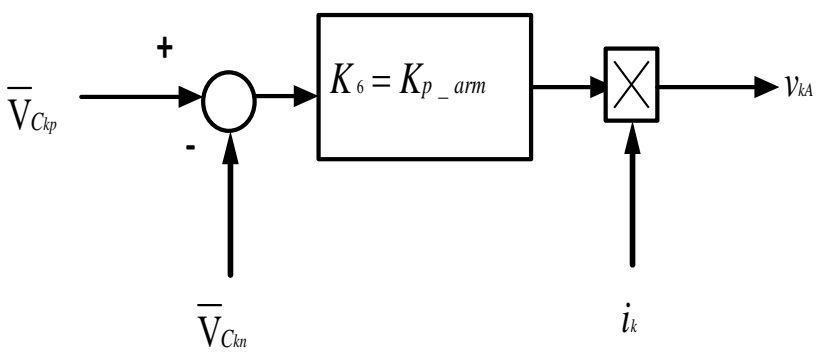

Figure 4. Arm balancing control block diagram

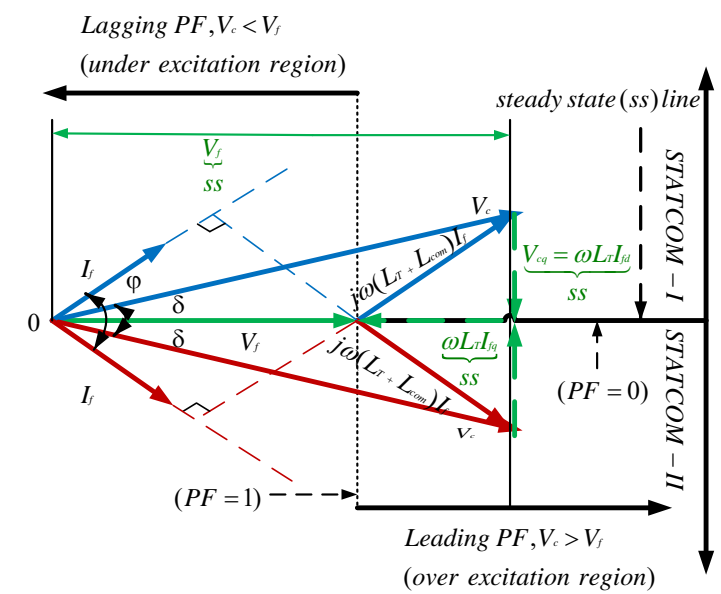

Figure 5. Combined Phasor diagram of voltage source grid connected STATCOMs for region I and II operations

Figure 2 depicts the averaging control diagram, this control pushes the average voltage $\bar{V}_{c k}$ of each phase leg to follow its reference voltage $\mathrm{V}_{c k}^{*}$. When $\mathrm{V}_{c k}^{*} \geq \overline{\mathrm{V}}_{c k}, i_{\text {cirk }}^{*}$ increases and forces the actual circulating current $i_{c i r k}$ to follow its reference current $i_{c i r k}^{*}$. This causes $\bar{V}_{c k}$ to track its reference voltage $V_{C k}^{*}$. PI controllers can be employed in the tracking, and the output voltage command $V_{\text {cirk }}$ from the averaging control can be produced for the CSPWM. The gains of the PI controllers which are $K_{1}, K_{2}, K_{3}$ and $K_{4}$ can be obtained based on internal mode control theory [32].

The individual balancing control pushes each SM capacitor voltage individually in every submodule to follow its voltage reference $V_{C k}^{*}$. The individual balancing control block diagram is depicted in

Figure. 3. The obtained voltage command for this modulation control is $V_{k B(i, j)}$. When $V_{C k}^{*} \geq V_{C k(i, j)}$, the arm current is charging the SM capacitors and the energy is being transferred from the DC link to the SM capacitors. The proportional controller $K_{5}$ can be employed as in [33] for the individual control.

The control block for the arm balancing control is shown in Figure. 4. This control lessens the discrepancies in voltages between the voltages of upper and lower arm. The P-controller with a gain $K_{6}$ can be employed in the control as in [33]. The voltage command for the arm control is $V_{k A}$.

\section{THE PROPOSED VOLTAGE COMPENSATION ALGORITHM $\left(\boldsymbol{V}_{\text {dcom }}\right.$ AND $\left.\boldsymbol{V}_{q c o m}\right)$ FOR MMC BASED STATCOM}

To control the reactive and active powers for the STATCOM applications, the d-axis and q-axis current control have to be as fast as possible. The conventional PI controllers usually employed, might have overshoots and longer-settling time [12]. The STATCOM variations/oscillations can occur due to the PI 
controllers delayed response, converter switching noise, waveform distortion when using fundamental frequency techniques, ripples from unbalanced capacitors, non-ideality or mismatch of the components [12].

The proposed control will be introduced to provide the MMC with additional compensation variables using the usual CSPWM. These compensation variables will be added as opposing signals to the PI control output variables (i.e. $Q_{d}$ and $Q_{q}$ ) [31] within the MMC control bandwidth for a fast current response with fewer overshoots. Unlike [29], where the use of any of PI-controllers was sacrificed and the steady-state condition was assumed in the current control. It can be seen in [29] that there were high current distortions during the transition of the load from capacitive to inductive mode.

This proposed control will utilize the low-distortion features of the PI controllers when compared with the hysteresis current controllers and adds transient support in the form of compensation variables ( $V_{\text {dcom }}$ and $V_{\text {qcom }}$ ) to achieve minimal distortion with an enhanced response. Since during the transients in Figure. 5, a small active power loss is associated with the effective resistance $R_{T}$, there will also be additional power loss within the number of SM capacitors [33]. Also, there is a small power loss from the voltage difference across the cumulative inductor $L_{T}$ considering the transient operations in STATCOM I region and STATCOM II region [31]. The STATCOM can attain steady-state faster when the active and the reactive variation impacts are compensated, and the STATCOM currents $I_{f d}$ and $I_{f q}$ will be driven to the desired currents $I_{f d}^{*}$ and $I_{f q}^{*}$ faster. This will happen when the inductance variation that can be obtained between the inductance at the steady-state and the inductance at transients is compensated [29]. Then, the current components $I_{f d}^{*}$ and $I_{f q}^{*}$ would have their resultant line current $I_{f}$ in quadrature with the available AC voltage at the PCC. And the AC voltage $V_{f}$ of the grid will also be in phase with STATCOM output AC voltage $V_{c}$. This means the STATCOM d-axis voltage command $V_{c d}^{*}$ will overcome the opposing voltage drop (i.e. $\omega L_{T} I_{f q}^{*}$ ) in Figure. 5, and $V_{c q}^{*}$ which is the resultant voltage command of the STATCOM q-axis would oppose the voltage drop $\omega L_{T} I_{f d}^{*}$.

From Figure. 5, the change in inductance value between the inductance at steady-state and inductance at transients due to high switching modulation will result to a small current degradation during the transients ( $\delta_{d}$ and $\delta_{q}$ ) given in (31) and (32)

$$
\begin{aligned}
& V_{c d}^{*}-V_{c d}=\Delta V_{c d} \\
& V_{c q}^{*}-V_{c q}=\Delta V_{c q}
\end{aligned}
$$

To counteract the voltage variations, which is indispensable in order to speed up the response of the PI controller, and reduce the current error in (31) and (32), a transient voltage can be derived from (2) with a compensating inductance $L_{\text {com }}$ as

$$
\Delta V_{q \mathrm{com}}=-L_{\mathrm{com}} \frac{d \delta_{q}}{d t}-\omega L_{\mathrm{com}} I_{f d}
$$

Therefore, the total steady-state interfacing inductance value $L_{T}$ will be modified to $L_{T c o m}$ only during the transients and are related as

$$
L_{T c o m} \geq L_{T}+L_{\text {com }}
$$

Assume the transient change in (37), happens during the time (i.e. $\Delta t$ ), putting (35) in (37) will give:

$$
\Delta V_{q c o m}=-L_{c o m} \cdot \frac{\left(I_{f q}^{*}-I_{f q}\right)}{\Delta t}-\omega L_{c o m} I_{f d}
$$


From Figure. 5, it can be seen that to cross into the region of the steady-state, the compensation can be applied during the transients (represented in red and blue line in Figure. 5) by overcoming the voltage difference due the effective inductance, this will push the resultant output voltage $V_{c}^{*}$ to reach as close as possible, its steady-state value at unity power factor line, assuming no variation due to STATCOM non-ideal operation, and no absorbed reactive power in the inductors ( $L_{f}$ and $L_{r}$ ).

Since the transient variation happens in every switching period, the switching frequency (i.e. $f_{s}$ ) can be estimated as the inverse of the transient time for the introduced compensation [29].

Therefore, the compensating voltage in the q-axis is as

$$
\Delta V_{\text {gcom }}=-f_{s} \cdot L_{c o m} \cdot \Delta I_{f q}-\omega L_{c o m} I_{f d}
$$

The corresponding d-axis active voltage compensation would be derived as:

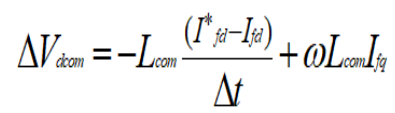

Similarly (39) is simplified as:

$$
\Delta V_{\text {dcom }}=-f_{s} \cdot L_{\text {com }} \cdot\left(\Delta I_{f d}\right)+\omega L_{\text {com }} I_{f q}
$$

During the transients, the voltage drop variables (i.e. $\omega L_{c o m} I_{f d}$ and $\omega L_{c o m} I_{f q}$ in (40) and (42) respectively can be compensated by the PI controllers; thus are ignored. Furthermore, the small distortions in the output $\mathrm{AC}$ voltage levels of the $\mathrm{MMC}$ due to the voltage disturbance between the upper and lower arms in each leg/phase can be considered [33]. Taking phase-k for instance, assume the entire SM voltages within the same phase arm are equal (which is possible if the capacitor voltage balance control in Figure. 2-4 are employed), as shown as

$$
v_{c k 1}=v_{c k 2}=. . v_{c k t}=\frac{V_{c k p}}{N}=\frac{V_{c k}+\Delta V_{c k p}}{N}=\frac{V_{c k}+\Delta V_{c k p}}{N}
$$

where $V_{C k p}$ and $V_{C k n}$ are the sum of SM capacitors voltages in the upper arm and lower arm of the phase-k leg, $V_{d c}$ is the total SM capacitors voltage measured which is equal to the steady-state value of $V_{c k p}$ and $V_{C k n} . N$ is the number of the SM in the upper and lower arm, $\Delta V_{c k p}$ and $\Delta V_{C k p}$ are the voltage change due to disturbances in the upper and lower arms respectively. The circulating current can be in form of a DC component $I_{d c}$ and harmonic components $i_{n}$ is given as

$$
i_{c r i k}=\frac{1}{3} i_{i c}+\sum_{n=1}^{\infty} i_{n}
$$

For typical STATCOM applications, the DC component $I_{d c}$ is zero as no DC voltage source is connected. The harmonic components $i_{n}$ are the nth order harmonic of the circulating current. The output AC voltage $V_{C k}$ and the output $\mathrm{AC}$ current $i_{k}$ in the phase-k leg are given as

$$
\begin{aligned}
& V_{c k}=\frac{1}{2} V_{c k} \cdot M \sin (\omega t) \\
& i_{k}=I_{0} \cdot \sin \left(\omega t-\varphi_{k}\right)
\end{aligned}
$$


$M$ is the voltage modulation index, $I_{0}$ is the peak amplitude output AC currents, $\varphi$ is the angle difference between the MMC output AC current with the PCC voltage.

Based on (43)-(44), the instantaneous active power of the upper and lower arm are:

$$
\begin{aligned}
& p_{a r m-k p}=\frac{1}{2} V_{d c}(1-M \sin (\omega t)) \cdot\left(\frac{i_{k}}{2}+\frac{1}{3} i_{k}+\sum_{n=1}^{\infty} i_{n}\right) \\
& p_{a r m-k n}=\frac{1}{2} V_{d c}(1+M \sin (\omega t)) \cdot\left(\frac{-i_{k}}{2}+\frac{1}{3} i_{c k}+\sum_{n=1}^{\infty} i_{n}\right)
\end{aligned}
$$

Summation of powers in (45) for the three-phases is supposed to be equal to the power $(P+Q)$ at the grid interface. These are related as

$$
P+Q=\frac{3}{2} \frac{V_{c q} V_{f d}}{\omega L_{T}}+\frac{3}{2} \frac{V_{c d} V_{f d}}{\omega L_{T}} \approx p_{a r m-u v w} \approx 3 \cdot p_{a r m-k}
$$

The corresponding active energy stored in the upper and lower arms of phase-k based on (45) are as follows:

$$
\begin{aligned}
& W_{p p}=\frac{1}{2 N} C V_{C \not p}^{2} \\
& W_{b s}=\frac{1}{2 N} C V_{C h n}^{2}
\end{aligned}
$$

Based on (45), (47), and (48) the following can be as

$$
\begin{aligned}
& \frac{d W_{k p}}{d t}=\frac{C}{N} \cdot V_{d c} \cdot \frac{d}{d t} V_{C h p}=p_{a r m-k p} \\
& \frac{d W_{k n}}{d t}=\frac{C}{N} \cdot V_{d c} \cdot \frac{d}{d t} V_{C r n}=p_{a r m-k n}
\end{aligned}
$$

Using (45), (49) and (50), the voltage disturbances in the arms which contribute to the MMC voltage variations can be as

$$
\left.\begin{array}{l}
\Delta V_{C n}=\frac{N}{2 C} \int(1-M \sin (\omega t)) \cdot\left(\frac{-i_{k}}{3}+\sum_{n=1}^{\infty} i_{n}\right) d t \\
\Delta V_{C p}=\frac{N}{2 C} \int(1+M \sin (\omega t)) \cdot\left(\frac{i_{k}}{3}+\sum_{n=1}^{\infty} i_{n}\right) d t
\end{array}\right\}
$$

Therefore, considering the variations in (51), the real output voltages of the upper and lower arms can be adjusted to: 


$$
\left.\begin{array}{l}
V_{k p}=\frac{1}{2}(1-M \sin (\omega t)) \cdot\left(V_{c k}+\Delta V_{C \not p}\right) \\
V_{k x}=\frac{1}{2}(1+M \sin (\omega t)) \cdot\left(V_{c c}+\Delta V_{C x n}\right)
\end{array}\right\}
$$

Then, the total output voltage can be given as

$$
\begin{aligned}
& V_{\phi p}+V_{k t}=V_{c k}+\frac{1}{2}\left(\Delta v_{c \phi p}+\Delta v_{c o t}\right)+\frac{1}{2} M \sin (\omega x) . \\
& \left(\Delta v_{C B t}-\Delta v_{C i \Phi}\right)=\left(V_{d x}+v_{k d}\right)
\end{aligned}
$$

Thus, $v_{k d}$ is the voltage variation between any of the MMC legs and the dc-link voltage (i.e. $V_{d c}$ ) when the system is under normal control and modulation. $v_{k d}$ is given as in (54).

$$
v_{k t}=\frac{1}{2}\left(\Delta v_{c p}+\Delta v_{c u}\right)+\frac{1}{2} M \sin (\omega t) \cdot\left(\Delta v_{c o n}-\Delta v_{c p}\right)
$$

This voltage disturbance between the upper and lower arms leads to the voltage difference between the three legs and the dc-link voltage [33]. Thus; (54) will contribute to the power difference between the right-hand side and the left-hand of (46). In other words, the active power difference will exist between the three-phase active power to be controlled at the grid using (25), and the sum of the three per-phase active powers which are per-phase controlled within the MMC using Figure. 2-4.This phenomenon would output the d-q components shown in Figure. 6. In other words, the arithmetical average dc capacitor voltage of all the phases, i.e. $\bar{V}_{C}(k)$ and the arithmetical mean dc capacitor voltage of each phase will produce voltage variation components. Using the d-q transform, it is possible from the voltage differences $\Delta \overline{\mathrm{V}}_{c k=u}, \Delta \overline{\mathrm{V}}_{c k=v}$ and $\Delta \overline{\mathrm{V}}_{C k=w}$ to obtain the d-q variation components $\Delta \bar{v}_{C d}$ and $\Delta \bar{v}_{C q}$. The variation components will be injected to reduce the second-harmonic oscillation of the capacitor voltages in order to reduce the capacitor voltage ripples/variation, thus; enhancing the active energy storage in the SM capacitorswithin the MMC system. The angle $\phi$ represents the extent of the voltage variation among the SM capacitors with respect to the STATCOM output currents in the $\mathrm{d}-\mathrm{q}$ frame and is given as

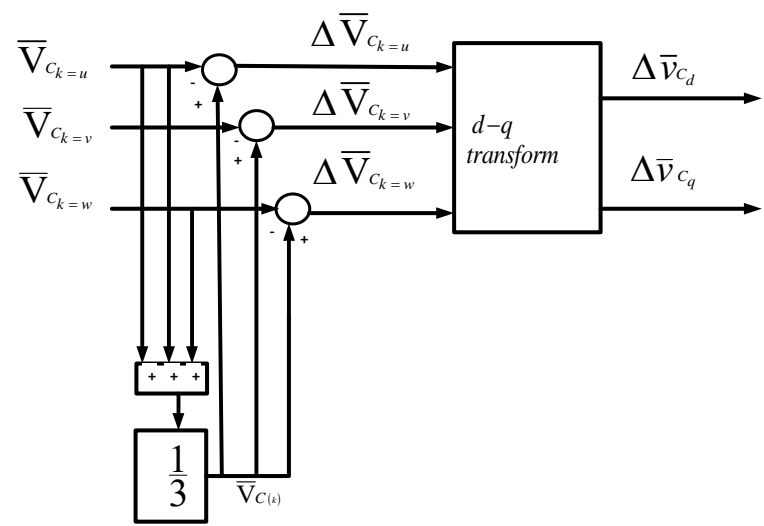

Figure 6. Arithmetical average capacitor voltage d-q variation 


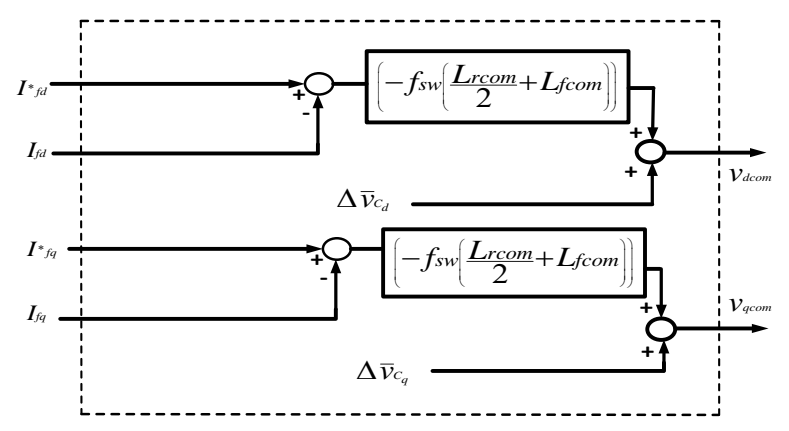

Figure. 7. Block diagram of the proposed d, q- compensation algorithm

$$
\phi=\tan ^{-1} \frac{I_{f q}}{I_{f d}}-\tan ^{-1} \frac{\Delta \bar{v}_{C q}}{\Delta \bar{v}_{C d}}
$$

The corresponding total voltage compensation in the d-q frame given in (38) and (40) can be augmented with the capacitor voltage signal as

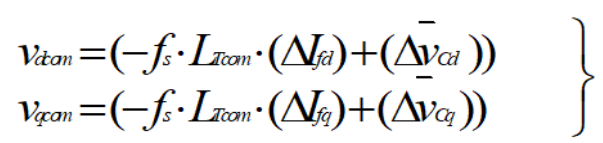

These two variables $\left(V_{\text {dcom }}\right.$ and $V_{\text {qcom }}$ ) will compensate the d-axis active voltage variation and provide the additional q-axis voltage support for the VAR compensation. The averaging control, individual control, and the arm balancing explained in Section II are employed in per-phase in this proposed control. From (56), it can be concluded that, once the variations due to the voltage disturbance which is responsible for capacitor variations, and the voltage difference due to the parameter variations of the STATCOM are resolved, (56) discontinues leaving behind the PI controller. The voltage compensation algorithm is represented in a control block diagram depicted in Figure. 7, and the proposed overall grid system is shown in Figure. 8.

Finally, the compensating variables ( $V_{\text {dcom }}$ and $V_{q c o m}$ ) are then added in (21) to generate the newly compensated voltage reference $\left(V_{c d}^{*}(k)\right.$ and $\left.V_{c q}^{*}(k)\right)$.

This means the voltage references described by (28) and (29) are modified as

$$
\begin{aligned}
& V_{c a l}^{*}(k)=-Q_{d}(k)+v_{c a m}(k)+V_{f d}(k)+\frac{\omega L_{T}}{2}\left(I_{f q}(k)+I_{f q}^{*}(k)\right)-R_{I f t}(k) \\
& V_{c q}^{*}(k)=-Q_{q}(k)+v_{q c o m}(k)+V_{f f}(k)-\frac{\omega L_{T}}{2}\left(I_{f i}^{*}(k)+I_{f i}(k)\right)-R_{I f} I_{f i}(k)
\end{aligned}
$$

\section{DISCUSSION AND RESULTS}

A five-level MMC is developed based on 4KHZ-CSPWM for the simulation and 16KHZ-CSPWM for the experiment.

\subsection{Simulation Results}

In order to authenticate the proposed control and its theoretical validity, two operating conditions of STATCOM (i.e. capacitive and inductive mode) are considered. Unlike [12], to optimize the performance of the proposed control, the compensating inductance in the block diagram of Figure. 7 is slightly changed as shown in Table 1. The reason for this inductance variation is to choose the best performing inductive effects (found to be Kv2 from Figure. 9). During transients, it has been reported that the filter inductance from the grid side would not remain fixed as measured at fundamental frequency [29]. Therefore, a modified value of inductance is needed during this transient support. The response of the voltage modulation index using the 
block diagram in Figure. 7 for the proposed control is shown in Figure. 9. The operation is changed to the inductive mode when the STATCOM current operation is in capacitive mode and has reached 0.4-second (12.5cycles). The response time for each operating condition is chosen small (1seconds) to ascertain the contribution of the proposed method. Since all the three-phases of MMC are identical, the response of phase$\mathrm{u}$ is presented (except in the case of Figure. 12, which illustrates the steady-state three-phase STATCOM voltages).

Figure 10(a) and Figure 10(b) show the MMC based STATCOM output reactive AC current during the control from capacitive to inductive state in a full response and expanded view response respectively. From the figures (i.e. Figure. 10(a) and Figure 10(b)), it can be seen that the conventional controlled reactive current has produced a delay of 0.1 seconds with more fluctuations. In other words, in the proposed control, the steady-state error and the transient response have improved. The d-axis component and its close view response have been shown in Figure 11(a) and Figure 11(b) respectively. It can be seen from the graph (Figure 11) that the proposed control technique has less overshoot during the control start-up time (0.00.1 seconds), and achieved a faster response with less current overshoots. The steady-state three-phase MMC based STATCOM AC output voltages using the proposed technique have been illustrated in Figure 12. Figure 13(a) and Figure 13(b) have shown the response of the q-axis and d-axis components of load current drawn from the grid respectively. It can be seen clearly that proposed current has settled faster than the conventional current control with 20\% time reduction. Figure 14 shows the upper arm current and Figure 15(a) shows the lower arm current. It can be seen in Figure 14 and Figure 15(a) that the proposed technique has fewer oscillations at the introduction of the reactive loads. The circulating current response is shown in Figure 15(b). The response has not fluctuated during the reactive step load change. This unchanged response during the transition shows that the dc circulating current control is minimally affected, thus; independent of the reactive load change.

In other words, since the active current reference $I_{c d}{ }^{*}$ obtained from the three-phase averaging voltage control (controlling the capacitors voltages), the output of the P-controller (i.e. K) is considered as the reference d-axis current and is found to be almost zero as expected for the STATCOM application as shown in Figure 11. Thus; the d-axis current response and the upper and lower arm currents responses are minimally affected by the step change in the reactive loads. Figure 16 shows load current per unit (p. u) from capacitive mode to inductive mode in full response, it can be seen that the conventional load current has some spikes and distortions at point 0.41 seconds, and at the time interval 0.42-0.43 seconds. These variations have equally been seen more clearly in their corresponding $d-q$ forms at the same time intervals in the q-axis current responses in Figure 10(a) and Figure 10(b). And in the d-axis responses in Figure 11(a) and Figure 11(b). Thus, the independent active and reactive power using the decoupled control has been achieved.

Table 1. Compensating inductance

\begin{tabular}{lll}
\hline $\begin{array}{l}\text { Compensating inductance } \\
\left(L_{\text {Tcom }}\right)\end{array}$ & Inductance increment & $\begin{array}{l}\text { Compensating term } \\
\left(\mathrm{K}_{\mathrm{V}}\right)\end{array}$ \\
\hline$L_{\text {Tcom1 }}$ & $+10 \%$ & $\mathrm{KV}_{1}$ \\
$L_{\text {Tcom } 2}$ & $+20 \%$ & $\mathrm{KV}_{2}$ \\
$L_{\text {Tcom3 }}$ & $-10 \%$ & $\mathrm{KV}_{3}$ \\
$L_{\text {Tcom4 }}$ & $-20 \%$ & $\mathrm{KV}_{4}$ \\
\hline
\end{tabular}

Table 2. Control parameters of the capacitor voltage balancing for MMC based STATCOM system

\begin{tabular}{lll}
\hline K1 & Proportional inner dc current gain & 0.16 \\
K2 & Integral inner dc current gain & 49 \\
K3 & Proportional dc capacitor voltage gain & 7.5 \\
K4 & Integral outer dc capacitor voltage gain & 375 \\
K5 & Proportional arm dc voltage gain & 0.5 \\
K6 & Proportional individual cap. dc voltage gain & 0.5 \\
\hline
\end{tabular}

Table 3. parameters of the grid connected MMC per-

\begin{tabular}{lll}
\multicolumn{2}{c}{ phase } \\
\hline$f$ & Fundamental frequency & $50 \mathrm{~Hz}$ \\
$f_{s w}$ & Switching frequency & $4 \mathrm{kHz}$ \\
$V_{f}$ & Grid voltage & $50 \mathrm{~V}$ rms \\
$R_{s}$ & Grid resistor & $0.500 \mathrm{~m} \Omega$ \\
$L_{s}$ & Grid inductor & $0.120 \mathrm{mH}$ \\
$R_{f}$ & AC coupling resistor & $0.100 \mathrm{~m} \Omega$ \\
$L_{f}$ & AC coupling inductor & $2 \mathrm{mH}$ \\
$R_{r}$ & MMC buffer resistor & $0.400 \mathrm{~m} \Omega$ \\
$L_{r}$ & MMC buffer inductor & $2 \mathrm{mH}$ \\
$C_{e}$ & Effective capacitor(s) & $8000 \mathrm{uF}$ \\
$V_{d c}$ & SM reference voltage & $50 \mathrm{~V}$ \\
$R L$ & Active -inductive Load (kw/Kvar) & $2 \mathrm{~K} / 2 \mathrm{~K}$ \\
$R C$ & Active-capacitive Load (kw/Kvar) & $2 \mathrm{~K} / 2 \mathrm{~K}$ \\
$K_{P} d, q$ & d-q-axis proportional current gain & 2800 \\
$K_{I \_d, q}$ & d-q-axis Integral inner current gain & 300 \\
\hline
\end{tabular}




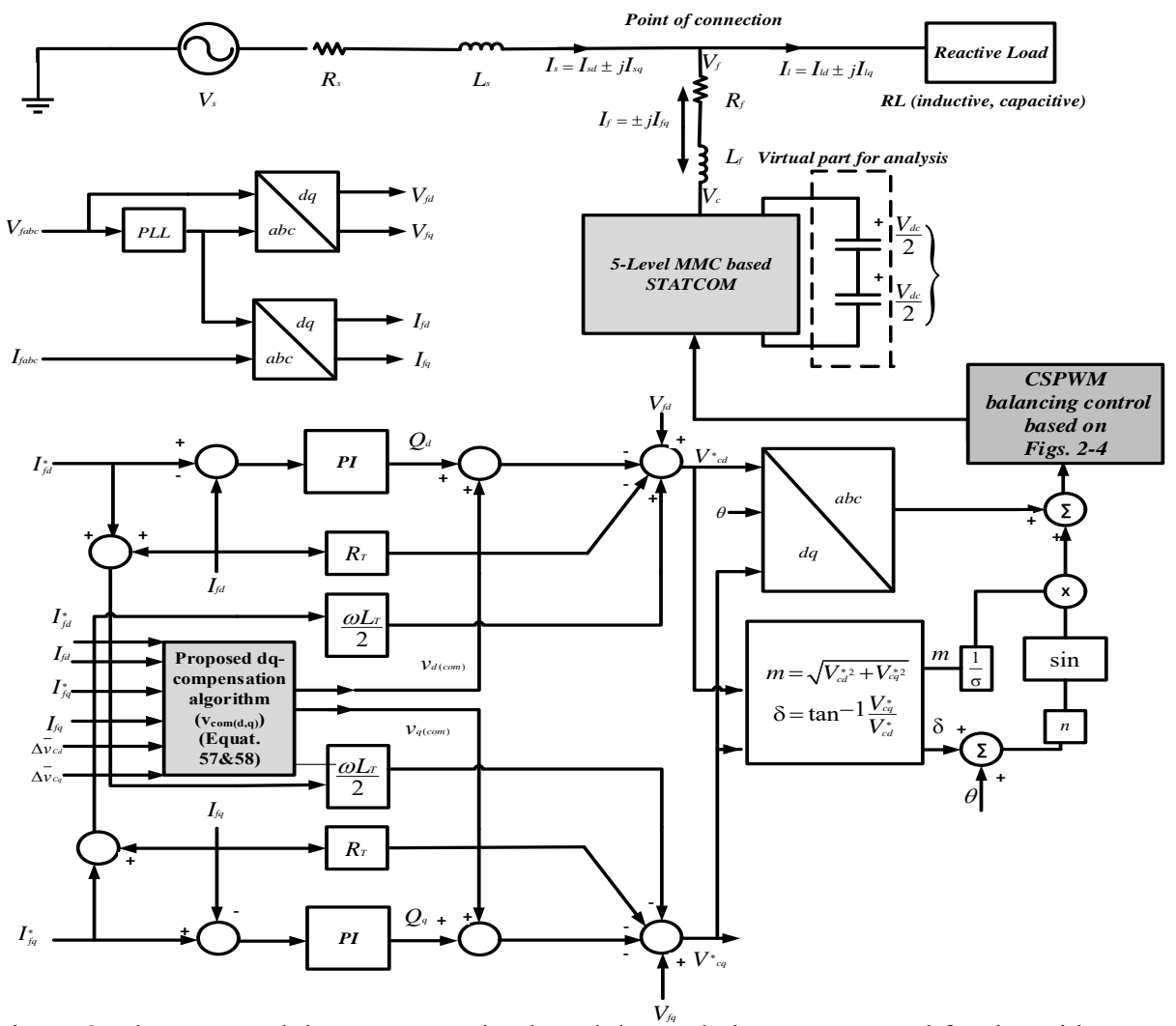

Figure 8. The proposed d,q-compensation based decoupled current control for the grid- MMC based STATCOM system

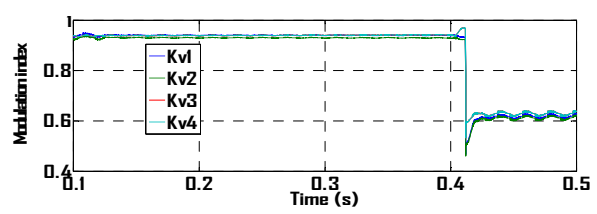

Figure 9. voltage modulating index selection response for the proposed control

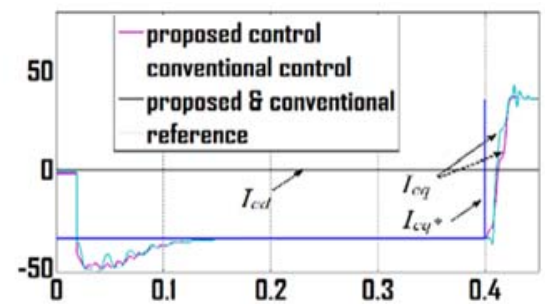

(a)

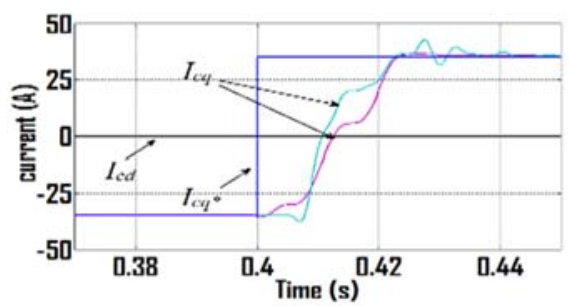

(b)

Figure 8. MMC based STATCOM output q-axis current with its reference current (a) full view response (b) expanded view response 


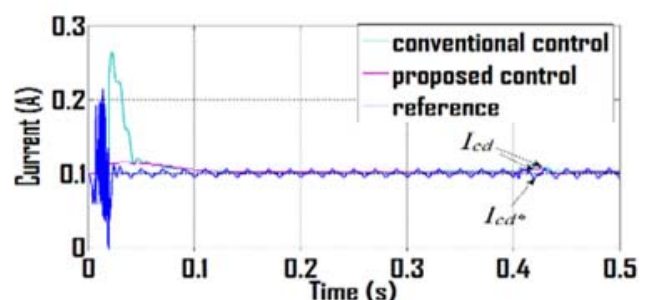

(a)

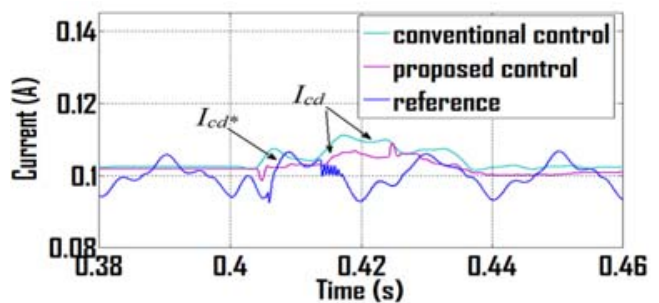

(b)

Figure. 9. MMC based STATCOM output d-axis current with its reference (a) full view response (b) expanded view response

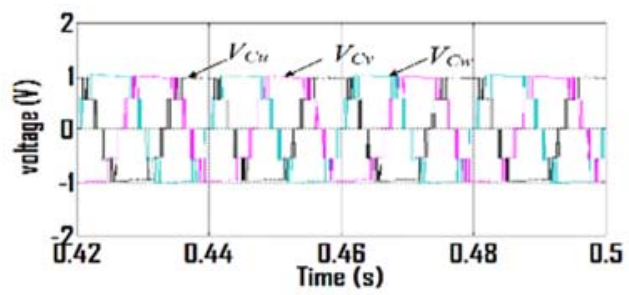

Figure. 10. Steady-state MMC based STATCOM AC voltages per unit (p. u)

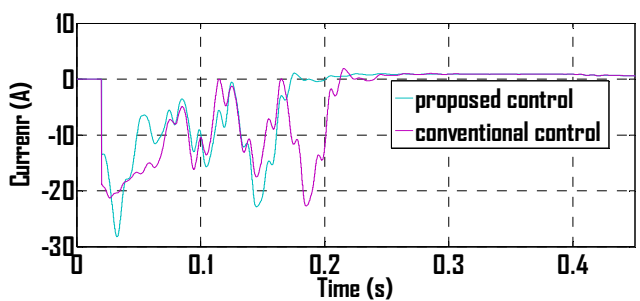

(a)

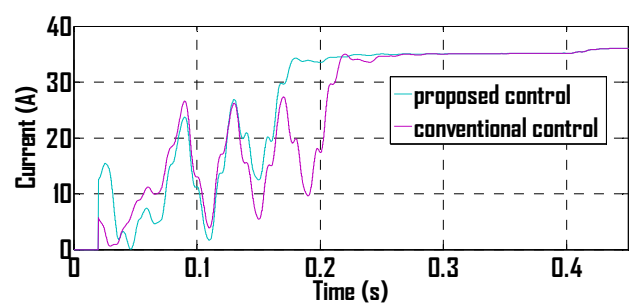

(b)

Figure 11. Grid current drawn by the load (a) q-axis current (b) d-axis current

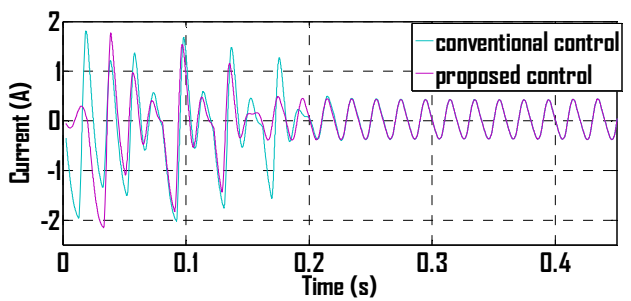

Figure 12. The MMC based STATCOM upper arm current 


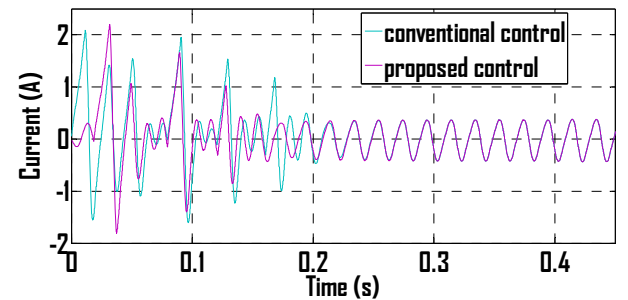

(a)

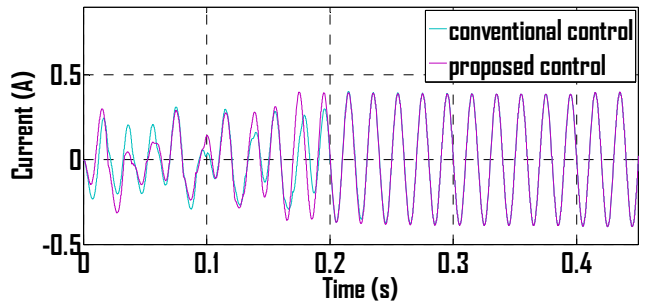

(b)

Figure 13. The MMC based STATCOM (a) lower arm current (b) Circulating current

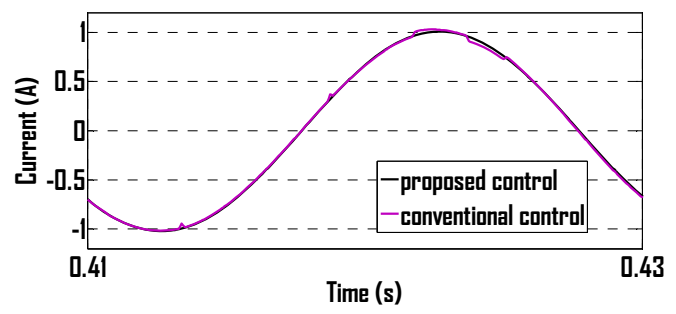

Figure. 14. The load AC current per phase per unit (p. u) from capacitive mode to inductive mode

\section{CONCLUSION}

This paper has investigated simplicity of carrier-based PWM technique in the STATCOM applications, afterwards, an enhancement on the performance of vector control based MMC is exploited. This has been achieved without the use of additional equipment or use of low switching complicated technique such the SHE. The proposed transient action introduced has helped in tackling the setback of dynamics of PI controllers and the STATCOM non-idealities; thus, it has enhanced the overall control system response of the MMC based STATCOM system. Finally, simulation are presented. In other words, the integral controllers of the inner current PI controllers have accepted the efforts provided by the transient compensators. This development can be used to achieve the practical realization of STATCOM with reduced variations.

\section{REFERENCES}

[1] L.K. Haw, M. Dahidah, N. Mariun, Cascaded multilevel inverter based STATCOM with power factor correction feature, 2011 IEEE Conf. Sustain. Util. Dev. Eng. Technol. Student. 1-7, 2011.

[2] F. Chouaf, S. Saad, "A New Structure of the Nine Level Inverter Used as Active Power Filter with a Reduced Number of Swiches," International Journal of Power Electronics and Drive Systems (IJPEDS), vol 9, no 1, pp. 198-209, 2018. doi:10.11591/ijpeds.v9n1.pp198-209.

[3] P. Rao, M.L. Crow, Z. Yang, "STATCOM control for power system voltage control applications," IEEE Trans. Power Deliv. vol, 15, pp. 1311-1317, 2000. doi:10.1109/61.891520.

[4] Y. Xu, F. Li, "Adaptive PI control of STATCOM for voltage regulation," IEEE Trans. Power Deliv. vol. 29, pp. 1002-1011, 2014. doi:10.1109/TPWRD.2013.2291576.

[5] H. Chen, M.H. Johnson, D.C. Aliprantis, "Low-frequency ac transmission for offshore wind power," IEEE Trans. Power Deliv. vol 28, pp. 2236-2244, 2013. doi:10.1109/TPWRD.2013.2266921.

[6] A. Shukla, A. Ghosh, A. Joshi, "State feedback control of multilevel inverters for DSTATCOM applications," IEEE Trans. Power Deliv. vol. 22, pp 2409-2418, 2007. doi:10.1109/TPWRD.2007.905271.

[7] Q. Song, W. Liu, Z. Yuan, "Multilevel optimal modulation and dynamic control strategies for STATCOMs using cascaded multilevel inverters," IEEE Trans. Power Deliv. vol. 22, pp. 1937-1946, 2007.

[8] V.L.P. Delivery, W. Li, "Very-High-Frequency Low-Voltage Power Delivery", (2013).

[9] K. Varalakshmi, R.L. Narasimham, G.T. Ramdas, "Eccentric operation of STATCOM Using Predictive Controller," International Journal of Power Electronics and Drive Systems (IJPEDS), vol 9, no 1, pp 150-156, 2018. doi:10.11591/ijpeds.v9n1.pp150-156.

[10] A.U. Lawan, "State Feedback Approaches for Designing A Statcom Supplementary Controller for Oscillations Damping," Int. J. Eng. Sci. vol. 3, pp. 27-37, 2014.

[11] N. Magaji, A.U. Lawan, A.D.O. Dan-isa, M.W. Mustafa, "Design A STATCOM supplementary Controller for Stability Studies using various state feedback algorithm," Recent Res. Circuits Syst. pp. 38-43, 2012.

[12] L.K. Haw, M.S.A. Dahidah, S. Member, H.A.F. Almurib, S. Member, "A New Reactive Current Reference 
Algorithmfor the STATCOM System Based on Cascaded Multilevel Inverters," IEEE Trans. POWER Electron. vol. 30, pp. 3577-3588, 2015.

[13] A.U. Lawan, M. Student, H. Abbas, J.G.K.S. M, A.A. Karim, "Dynamic performance of Improvement of MMC Inverter with STATCOM Capability interfacing PMSG Wind Turbines with Grid," 2015 IEEE Conf. Energy Convers. pp. 492-497, 2015.

[14] A.U. Lawan, M. Mustapha, I. Abubakar, M. Mustapha, I. Abubakar, "Reactive current control of STATCOM based MMC Inverter for Wind Turbines connected to Grid," 2015 IEEE Student Conf. Res. Dev. pp. 26-31, 2015.

[15] L. Haw, M.S. a Dahidah, H. a F. Almurib, "SHE-PWM Cascaded Multilevel Inverter With Adjustable DC Voltage Levels Control for STATCOM Applications," Power Electron. IEEE Trans. vol. 29, pp. 6433-6444, 2014. doi:10.1109/TPEL.2014.2306455.

[16] T. Porselvi, K. Deepa, R. Muthu, "FPGA Based Selective Harmonic Elimination Technique for Multilevel Inverter," International Journal of Power Electronics and Drive Systems (IJPEDS), vol 9, no 1, pp. 166-173, 2018. doi:10.11591/ijpeds.v9n1.pp166-173.

[17] A.U. Lawan, N. Magaji, H. Musa, "A STATCOM Controller for Small Signal Stability using Polynomial Algorithms in a Horizontal Axis Wind Farm Power System," 2013 IEEE Energytech USA. pp. 1-5, 2013.

[18] H. Daniyal, E. Lam, L.J. Borle, H.H.C. Iu, "Hysteresis, PI and Ramptime Current Control Techniques for APF: An experimental comparison," Proc. 2011 6th IEEE Conf. Ind. Electron. Appl. ICIEA 2011. pp. 2151-2156, 2011. doi:10.1109/ICIEA.2011.5975947.

[19] P.K. Jin, M.S.A. Dahidah, C. Klumpner, "Nine-Level SHE-PWM VSC Based STATCOM for VAR Compensation," IEEE 2010 IEEE Int. Conf. Power Energy, pp. 135-140, 2010.

[20] S. Enhancement, Stability Enhancement, (2008) 24-29.

[21] K. Sundararaju, A. Kumar, "Cascaded Control of Multilevel Converter based STATCOM for Power System Compensation of Load Variation, Int." ... 40 (2012) 30-35. doi:10.5120/4954-7206.

[22] Z. Guangming, W. Maojun, G. Qiang, Z. Dantian, Y. Bin, Q. Wei, Y. Peng, "A Research on Control Strategy of STATCOM based on Particle Swarm Optimization Algorithm," (2015) 745-748.

[23] C.H. Liu, Y.Y. Hsu, Design of a self-tuning pi controller for a STATCOM using particle swarm optimization, IEEE Trans. Ind. Electron. vol 57, pp. 702-715, 2010. doi:10.1109/TIE.2009.2028350.

[24] J. Dalei, K.B. Mohanty, S. Singh, G.S. Garain, "Fuzzy PI controller for improved voltage regulation in STATCOM based SEIG," 2 (n.d.) 2-6. doi:10.1109/INDICON.2015.7443154.

[25] A. Luo, C. Tang, Z. Shuai, J. Tang, X.Y. Xu, D. Chen, "Fuzzy-PI-based direct-output-voltage control strategy for the STATCOM used in utility distribution systems," IEEE Trans. Ind. Electron. vol 56, pp. 2401-2411, 2009. doi:10.1109/TIE.2009.2021172.

[26] J.I.Y. Ota, Y. Shibano, H. Akagi, "A Phase-Shifted PWM D-STATCOM Using a Modular Multilevel Cascade Converter ( SSBC ) - Part II : Zero-Voltage-Ride-Through Capability," IEEE Trans. Ind. Appl. vol. 51, pp. 289296, 2015.

[27] F. Botterón, H. Pinheiro, H. a Gründling, J.R. Pinheiro, H.L. Hey, "A. Normalization, Digital voltage and current controllers for three-phase PWM inverter for UPS applications," 0 (2001) 2667-2674.

[28] J.I.Y. Ota, Y. Shibano, N. Niimura, H. Akagi, "A Phase-Shifted-PWM D-STATCOM Using a Modular Multilevel Cascade Converter (SSBC): Part I. Modeling, Analysis, and Design of Current Control," IEEE Trans. Ind. Appl. 9994 1-1, 2014. doi:10.1109/TIA.2014.2326079.

[29] W.L. Chen, C.Z. Xie, "Active voltage and frequency regulator design for a wind-driven induction generator to alleviate transient impacts on power grid," IEEE Trans. Ind. Electron. vol 60, pp. 3165-3175, 2013. doi:10.1109/TIE.2012.2200212.

[30] L. Maharjan, S. Inoue, H. Akagi, "A transformerless energy storage system based on a cascade multilevel PWM converter with star configuration," IEEE Trans. Ind. Appl. vol. 44, pp. 1621-1630, 2008. doi:10.1109/TIA.2008.2002180.

[31] S.A. Azmi, G.P. Adam, K.H. Ahmed, S.J. Finney, B.W. Williams, "Grid interfacing of multimegawatt photovoltaic inverters," IEEE Trans. Power Electron. vol. 28, pp. 2770-2784, 2013. doi:10.1109/TPEL.2012.2219072.

[32] M. Hagiwara, H. Akagi, "PWM Control and Experiment of Modular Multilevel Converters," (2008) 154-161.

[33] M. Zhang, L. Huang, W. Yao, Z. Lu, "Circulating harmonic current elimination of a CPS-PWM-based modular multilevel converter with a plug-in repetitive controller," IEEE Trans. Power Electron. vol. 29, pp. 2083-2097, 2014. doi:10.1109/TPEL.2013.2269140. 